\title{
UTERINE DYDELPHYS WITH PREGNANCY IN RIGHT CORNU
}

Mandavi Rai ${ }^{1}$, Pratima Thamke², Archana Chatterjee ${ }^{3}$, Amit Kulkurani ${ }^{4}$

\section{HOW TO CITE THIS ARTICLE:}

Mandavi Rai, Pratima Thamke, Archana Chatterjee, Amit Kulkurani. "Uterine Dydelphys with Pregnancy in Right Cornu". Journal of Evolution of Medical and Dental Sciences 2014; Vol. 3, Issue 24, June 16; Page: 6644-6648, DOI: $10.14260 /$ jemds/2014/2796

ABSTRACT: Uterus Didelphys is also known as duplicated uterus. It is an embryological abnormality resulting from complete failure of fusion of Mullerian ducts. There is presence of two uterine horns and two cervices with no communication between endometrial and endocervical cavities. We report the case in our institute of single viable pregnancy in right sided uterine body of didelphic uterus. She was an unbooked case and baby was delivered at twenty nine weeks of gestation by caesarean section as she reported to us with preterm labour with breech presentation. She had an uncomplicated post-operative period.

INTRODUCTION: Uterus didelphys occurs when 2 mullerian ducts develop normally but they fail to fuse giving complete duplication of uterine horns and cervices with no communication between duplicated endometrial or endocervical cavities. It comprises of $5 \%$ of mullerian duct anomalies. ${ }^{(1,2)}$

It can result in obstetric complications such as spontaneous abortion, preterm labour, cervical incompetence and malpresentations. There may be associated complications of transvaginal septum which causes obstructions and hematocolpos and there is increased risk of endometriosis if there is obstruction due to retrograde menstrual flow. It can be associated with urinary tract abnormalities.(1) Incidence varies from 1 in 1500 to 1 in 1,32,000 pregnancies worldwide. $(2,9,12)$

\section{EMBRYOLOGY:}

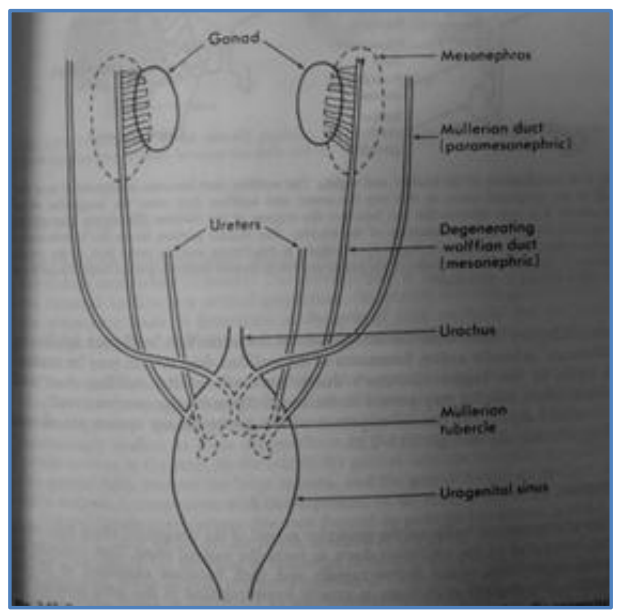

At six weeks of fetal life both males and females genital tracts have paired paramesonephric (Mullerian) duct and mesonephric (Wolffian) ducts. In females the mesonephric ducts degenerate and by twelve weeks due to lack of testosterone and the paired paramesonephric developed on lateral aspect of mesonephrons to reach urogenital sinus at nine weeks and unfused lateral arms of paramesonephric ducts forming fallopian tubes. 
Paired sinovaginal bulb on posterior aspect of urogenital sinus fuse with lower end of mullerian duct to form vaginal plate. Mullerian ducts undergo internal canalization which results in two lumen divided by midline septum. Reabsorption of septum occurs in caudal to cranial direction. The two mullerian ducts fuse to form single uterine body.

If fusion does not occur properly, developmental failure leads to various uterine anomalies. Different type includes category I: Hypoplasia/ agenesis Category II: Unicornuate uterus Category III: Didelphys Category IV: Bicornuate Category V: Septate category VI: arcuate. ${ }^{(5,7)}$

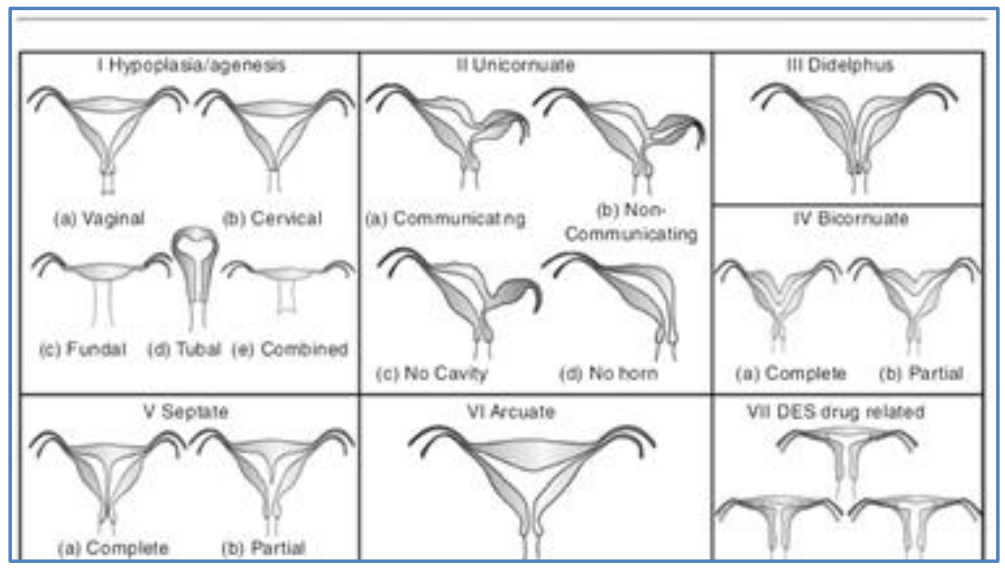

CASE: 22Years old $\mathrm{G}_{4} \mathrm{P}_{2} \mathrm{~L}_{0} \mathrm{~A}_{1}$ unregistered presented to outpatient department with seven months amenorrhea and pain in abdomen since four to five hours. She gave a history of previous diagnostic tests (Hysterosalpingography and USG) showing two uterine horns and two cervices with both kidney and ureter being normal. Her vitals were within normal parameters. She had an earlier history of neonatal death three years back in which baby was delivered vaginally at six months amenorrhea and expired three days after birth.

Second baby died two years back which was also delivered at six month. She had history of abortion at three months one year back for which dilatation and curettage was done. She had no significant past or family history. Her vital parameters were normal. On perabdomen examination, uterus appeared to be 28-29 weeks. Uterine contour suggested presence of pregnancy in right sided uterine horn. Baby was in breech presentation.

Complete Vertical Vaginal Septum was seen in per speculum examination and separate cervix on each side of vaginal septum is seen. USG examination confirmed single pregnancy with 29 wks gestation in one horn with breech presentation with normal cardiac activity and AFI $4 \mathrm{cms}$ and weight of the baby 1330gms. On per vaginal examination, she was two fingers loose and 40-50\% effaced. At first we tried to conserve the pregnancy by putting her on tocolytics and giving her dose of betamethasone.

But since her contraction did not subside she was posted for emergency LSCS. On Opening the abdomen, pregnancy was seen in the right cornu and baby was delivered as breech presentation. Placenta was separated after delivery two completely separated cornu of uterus was seen with one tube and ovary attached to each horn with no communication with endometrial cavity. Patient had an uneventful post-operative period and baby was kept in neonatal intensive care unit for observation and further management. 
DISCUSSION: Congenital defects of the reproductive tract are often associated with premature labour, abnormal presentations and increased necessity for caesarean section as if normal labour tried there can be chances of rupture.(3,5,10) So the recent trend for mode of delivery is Caesarean section. $(4,10,11)$ Although pregnancy period may be uneventful but there is low percentage of viable pregnancies as compared to normal.

Detection of uterine anomalies in early pregnancy is of great importance. Ultrasonography demonstrates widely divergent uterine horns with two distinct cervices and no connecting endometrium. Transvaginal sonography offers a new reliable diagnostic method in predicting uterine anomalies in very early stage of pregnancy. Uterus didelphys is best appreciated on MRI with corneal oblique $\mathrm{T}_{2}$ weighted images. In this it is possible to image two uterine horns and two cervices with normal appearance of endometrial and myometrial layers. $(5,6,7,12)$

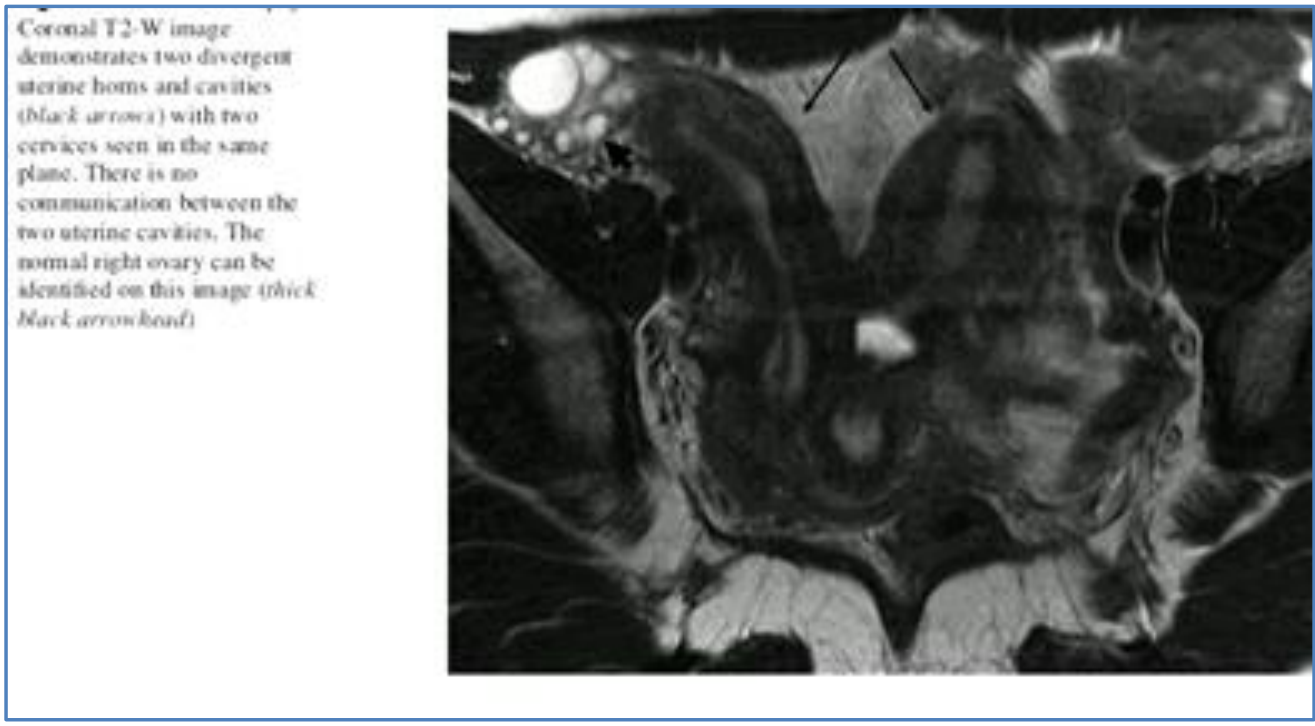

Different reproductive outcome of uterine anomalies include $(8,9.10,11,12)$

\begin{tabular}{|llllllll}
\hline $\begin{array}{l}\text { Uterine } \\
\text { anomaly }\end{array}$ & $\begin{array}{l}\text { Number } \\
\text { of studies }\end{array}$ & $\begin{array}{l}\text { Number } \\
\text { of patients }\end{array}$ & $\begin{array}{l}\text { Number } \\
\text { of pregnancies }\end{array}$ & $\begin{array}{l}\text { Abortion } \\
\text { rate }\end{array}$ & $\begin{array}{l}\text { Preterm } \\
\text { birth rate }\end{array}$ & $\begin{array}{l}\text { Term delivery } \\
\text { rate }\end{array}$ & $\begin{array}{l}\text { Live birth } \\
\text { rate }\end{array}$ \\
\hline Unicornuate & 11 & 151 & 250 & 36.5 & 16.2 & 44.6 & 54.2 \\
\hline Didelphys & 8 & 114 & 152 & 32.2 & 28.3 & 36.2 & 55.9 \\
\hline Bicornuate & 4 & 261 & 627 & 36 & 23 & 40.6 & 55.2 \\
\hline Septate & 4 & 198 & 499 & 44.3 & 22.4 & 33.1 & 50.1 \\
\hline Arcuate & 3 & 102 & 241 & 25.7 & 7.5 & 62.7 & 66 \\
\hline
\end{tabular}

\section{REFERENCES:}

1. Danielle M. Allegrezza, RT R, RDMS. Journal of Diagnostic Medical Sonography 2007; 23: 286289.

2. Brody, S.K. Double Uterus with Double Pregnancy1957; 67: 161-167.

3. Green LK, Harris RE. Uterine anomalies; frequency of diagnosis and associated obstetric complications. Obstet Gynecol 1976; 47: 427-429. 


\section{CASE REPORT}

4. Pritchard J, MacDonald P, Gant NF. (eds) Williams Obstetrics, 17th edn, Abnormalities of the reproductive tract. Norwalk CN: Appleton, Century, crofts, 1985: 494-497.

5. Haid C, Zech H, Martin J. Verbesserte Friih diagnose der intrauterinen Schwangerschaft durch Ultraschall - Vaginalsonde. Geburts Frauenheilk 1985; 45: 371-374.

6. Kanakas N, Boos R, Schmidt W. Vaginosonographische Follikulometrie. Ultraschall Klin Prax 1988; 3:13-18.

7. Rempen A. Vaginale Sonographie der intakten Graviditaet im ersten Trimenon. Geburtsh Frauenheilk 1987; 47: 477-482.

8. Pittock ST, Babovic-Vuksanovic D, Lteif A. Mayer-Rokitansky-Kuster-Hauser anomaly and its associated malformations. Am J Med Genet A. 2005; 135 (3): 314-6.

9. Rackow BW, Arici A. Reproductive performance of women with Mullerian anomalies. Curr Opin Obstet Gynecol. 2007; 19 (3): 229-37.

10. Simpson Jr WL, Beitia LG, Mester J. Hysterosalpingography: a re-emerging study. Radiographics. 2006; 26 (2): 419-31.

11. Troiano RN, McCarthy SM. Mullerian duct anomalies: imaging and clinical issues. Radiology. 2004; 233 (1): 19-34.

12. Wolfman DJ, Ascher SM. Magnetic resonance imaging of benign uterine pathology. Top Magn Reson Imaging. 2006; 17: 399-407.

\section{PREOP AND INTRAOP FINDINGS:}

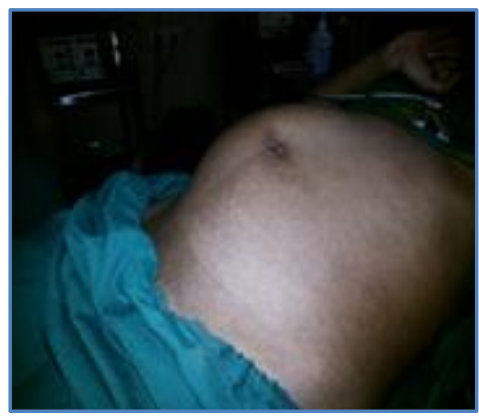

\section{Pre-op findings -Right side deviation of uterus}

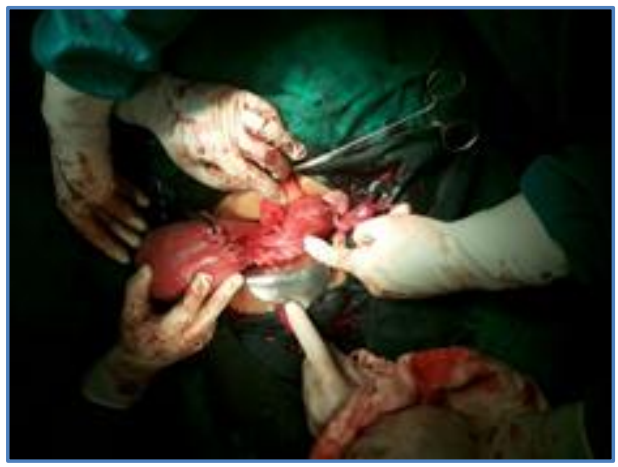




\section{CASE REPORT}
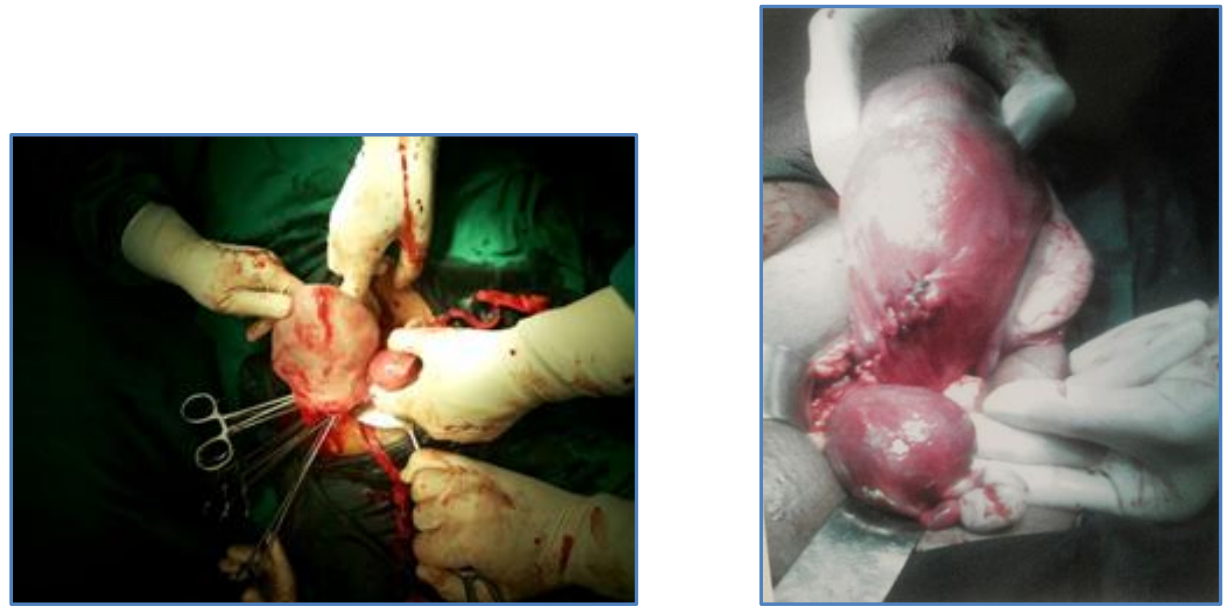

\section{Intra-op findings showing two cornus of uterus with attachment of fallopian tubes on each side}

\section{AUTHORS:}

1. Mandavi Rai

2. Pratima Thamke

3. Archana Chatterjee

4. Amit Kulkurani

\section{PARTICULARS OF CONTRIBUTORS:}

1. $2^{\text {nd }}$ year Post Graduate Student, Department of Obstetrics and Gynaecology, Mahatma Gandhi Mission Medical College and Hospital. Kalamboli, Navi Mumbai.

2. Lecturer, Department of Obstetrics and Gynaecology, Mahatma Gandhi Mission Medical College and Hospital. Kalamboli, Navi Mumbai.

3. Associate Professor, Department of Obstetrics and Gynaecology, Mahatma Gandhi Mission Medical College and Hospital. Kalamboli, Navi Mumbai.
4. 2nd year Post Graduate Student, Department of Obstetrics and Gynaecology, Mahatma Gandhi Mission Medical College and Hospital. Kalamboli, Navi Mumbai.

\section{NAME ADDRESS EMAIL ID OF THE CORRESPONDING AUTHOR:}

Dr. Mandavi Rai,

Post Graduate Student $2^{\text {nd }}$ Year, M. G. M Hospital, P. G. Hostel, Kamothe, Navi Mumbai-410209.

E-mail: mandavirai@ymail.com

Date of Submission: 22/05/2014.

Date of Peer Review: 23/05/2014.

Date of Acceptance: 04/06/2014.

Date of Publishing: 12/06/2014. 